\title{
Time of concentration for large catchment based on hydrodynamic modelling
}

\author{
Hassan Abd Jali1 ${ }^{1,}$, Harun Sobri $^{1}$, and Ismail Tarmizi ${ }^{1}$ \\ ${ }^{1}$ Department of Hydraulics and Hydrology, Faculty of Civil Engineering, \\ Universiti Teknologi Malaysia, 81310 Skudai, Johor, Malaysia
}

\begin{abstract}
Flood mitigation design requires accurate computation of discharge at any interest location to sustain the protection level. The design flood hydrograph generates from rainfall runoff model which used unit hydrograph method depends on the time of concentration $\left(T_{c}\right)$ of the catchment. Common factors which influence $T_{c}$ are the catchment properties including length, slope, soil properties and surface cover. However, when dealing with large catchment, more complex factors which also requires attention are the rainfall intensity, catchment wetness and initial water in the channel due to rain prior to the storm event. For large catchment, the travelling time which govern the $T_{c}$ is more dominant in the channel rather than on the soil surface. Since water flowing in the river channel is unsteady and nonuniform, the use of Manning formula is inappropriate. This paper explains the application of hydrodynamic modelling approach to determine $T_{c}$ for large catchment with long river channel. A hydrodynamic river model for Sg Relai, Kelantan with area of $460 \mathrm{~km}^{2}$ and covering $90 \mathrm{~km}$ distance was developed using InfoWorks ICM. Results shown that as the rain intensity increased, the travelling time will be shortened. The traveling time also reduce when initial water level in the channel increase which indicate that $T_{c}$ will reduce if the catchment already received some rainfall prior to the storm event. Based on this analysis and results, the use of hydrodynamic model as part of the rainfall runoff model is significant for large catchment to handle complex factor such as wide range of rainfall intensity, spatial effect and catchment wetness.
\end{abstract}

\section{Introduction}

Time of concentration $\left(\mathrm{T}_{\mathrm{c}}\right)$ is define as time for wave to travel from the hydraulically most distant point of the catchment to a point of interest within the catchment [1]. It is one of the important input to the rainfall runoff model for the purpose of generating flood hydrograph. Factors affecting $T_{c}$ are surface roughness, channel shape and flow patterns and slope. Furthermore, the effect of rainfall intensity can be seen in Izzad and Kinematic wave formula [2].

* Corresponding author: abdjalil.hassan@gmail.com 
Many method are available to estimate $T_{c}$ such as Kirpich, SCS lag and Velocity. Kaufmann de Almeida et al. [3] compared twenty $T_{c}$ equations ranging from very small catchment of $0.01 \mathrm{~km}^{2}$ to $70,000 \mathrm{~km}^{2}$ for the site in tropical region. However, since too many formulae with many factors to consider, it's become complicated especially for new hydrologist to choose the appropriate method without proper guidance from the experience hydrologist. The absent of observed data may lead to difficulty to develop a reliable rainfall runoff model.

To overcome this problem, a simple but systematic approach should be established using powerful hydrologic and hydraulic tools for the development of rainfall runoff model $\mathrm{Sg}$ Relai which is tributaries of Sg Lebir in Sg Kelantan basin had been selected for the study on how the $T_{c}$ can be determined under various factors variation.

This paper elaborates the use of hydrodynamic approach to determine $T_{c}$ under complex situation such as variation of rainfall intensity and catchment wetness.

\subsection{Objectives}

The hydrodynamic model is develop to:

i. Examine the effect of different rainfall intensity on the $\mathrm{T}_{\mathrm{c}}$.

ii. Examine the effect of catchment wetness on the $\mathrm{T}_{\mathrm{c}}$.

\section{Study area}

Sg. Relai is one of the major tributaries of Sg Lebir with the river length is about $100 \mathrm{~km}$. It is located at the east coast of Peninsular Malaysia and subjected to the North east monsoon prevail from October to March and the heavy raining month is between November to December. The catchment area is approximately $460 \mathrm{~km}^{2}$. Fig. 1 shows the location and the river system of Sg Relai and Sg Lebir. The catchment is mainly covers with forest and agriculture. It was selected due to the good and reliable data available for the development of the model.

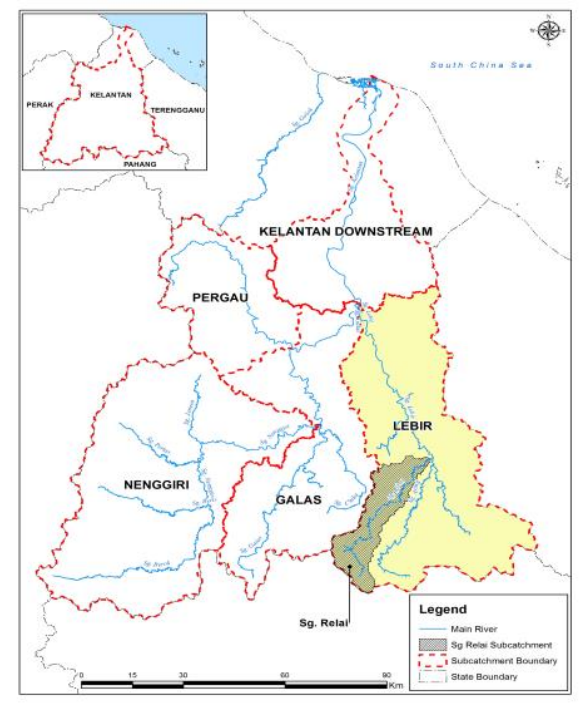

Fig. 1. Location of Sg Relai and Sg Lebir. 


\section{Methodology}

The estimation of $\mathrm{T}_{\mathrm{c}}$ recommended by USDA-NRCS [1] is to separate the travel time for sheet flow, shallow concentrated flow and open channel flow. Normally, channel flow used Manning equation which highly depend on the channel slope. However, where channel is mild, backwater effect may change the speed of the flow. The present of large water body also influence the speed of flood wave which in this case requires the wave celerity contribution. To eliminate the problem of the flow variation due to the channel properties and different flow changes, a hydrodynamic model shall be built to cover the large component of the channel. The model shall contains channel covering about $90 \%$ of the total catchment length. The channel properties will be extracted from the Digital Terrain Model (DTM) which come in the format of Interferometric Synthetic Aperture Radar (IFSAR) with accuracy of $\pm 1 \mathrm{~m}$. The hydrodynamic model shall deployed the dynamic wave equation (St Venant equation) [2] as shown below.

Continuity equation:

$$
\frac{\partial Q}{\partial x}+\frac{\partial A}{\partial t}=0
$$

Momentum equation:

$$
\frac{1}{A} \frac{\partial Q}{\partial t}+\frac{1}{A} \frac{\partial}{\partial x}\left(\frac{Q^{2}}{A}\right)+g \frac{\partial y}{\partial x}-g\left(S_{o}-S_{f}\right)=0
$$

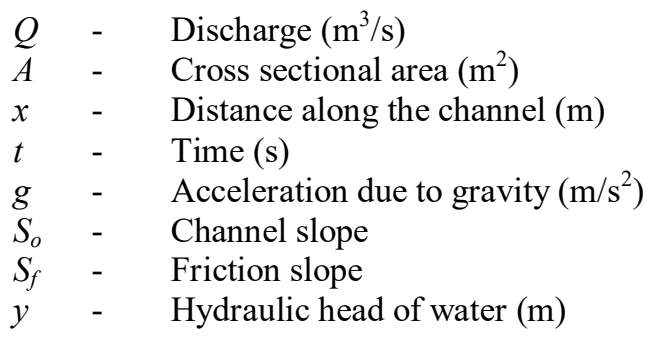

Two scenarios to be investigated are:

i. The effect of rainfall intensity.

- This is represented by different discharge at the upstream of the model.

ii. The effect of catchment wetness.

- This is represented by different water depth in the channel using different initial discharge. 
To capture the backwater effect, the hydrologic model is build using the hydrodynamic method.

\subsection{Software selection}

Software used in the study is InfoWorks ICM developed by Innovyze U.K [4]. The software deployed the full St Venant equation for the flood wave propagation in shallow water. It is capable to simulate hydrology and hydraulic in a single run including the delineation of flood extent. The software incorporate both urban and river catchment. With full integration of 1D and 2D modelling technique both the below and above ground elements can be modelled in as a full system.

\subsection{Data Collection}

To ensure the success of the analysis some of the data requires are:
i. DTM
ii. River system
iii. Contour
iv. Satellite image

Fig. 2(a) and Fig. 2(b) show the river system, contour and DTM of the study area, respectively.

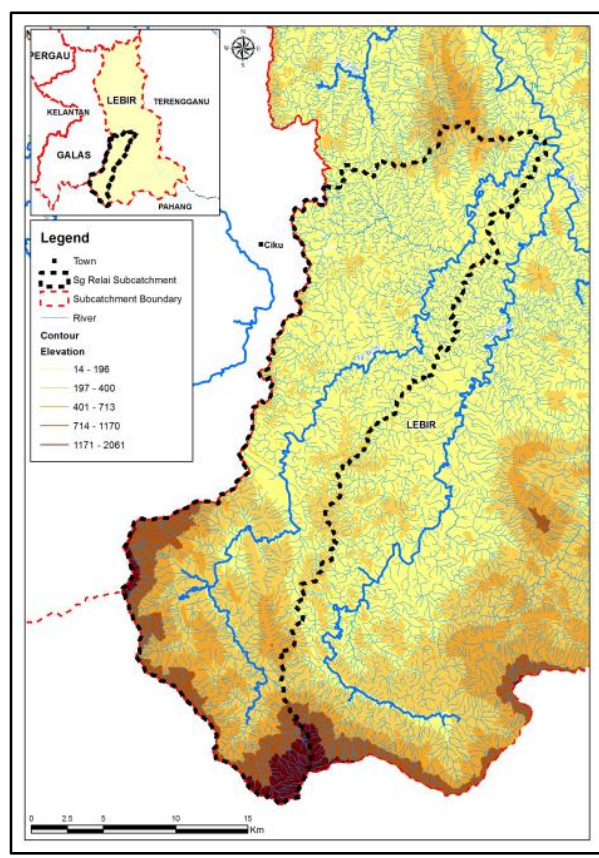

(a)

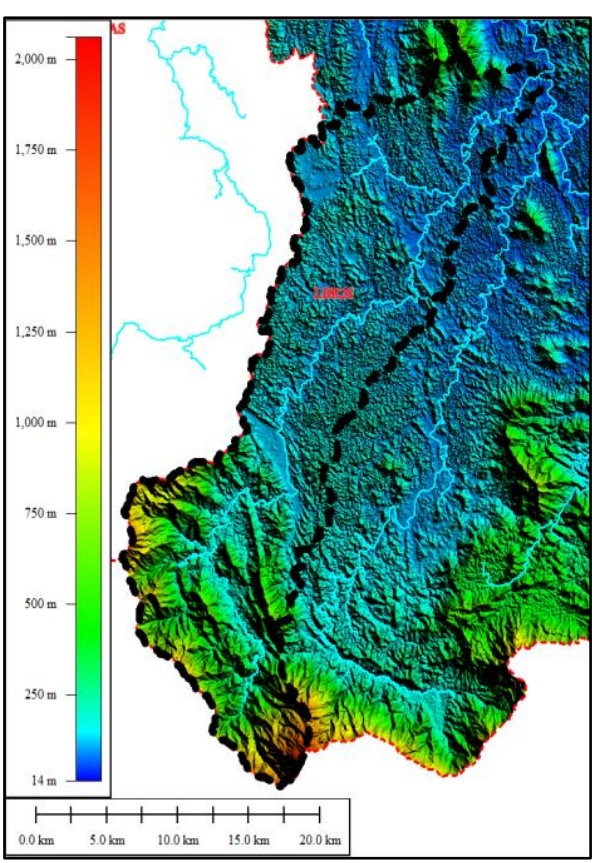

(b)

Fig. 2. (a) Sg Relai river system; and (b) digital terrain model for Sg Relai. 


\subsection{Modelling processes}

The rainfall runoff model was develop using hydrodynamic model. DTM was used to extract the river cross section at 2-3 km interval which covers $90 \mathrm{~km}$ distance as shown in Fig. 3 and Fig. 4. A synthetic triangular hydrograph to represent for different intensity ranging from $10 \mathrm{~m}^{3} / \mathrm{s}$ to $100 \mathrm{~m}^{3} / \mathrm{s}$ was develop and applied at the most upstream of the channel. To examine the effect of catchment wetness, an initial value of discharge was added into the channel. This initial flow is allow to flow in the channel for certain period of time before the flood hydrograph enter the model. This initial flow will ensure the channel is fill up with water before the actual flood hydrograph is rout in the model. The initial flow ranges from $0 \mathrm{~m}^{3} / \mathrm{s}$ as dry to $30 \mathrm{~m}^{3} / \mathrm{s}$.

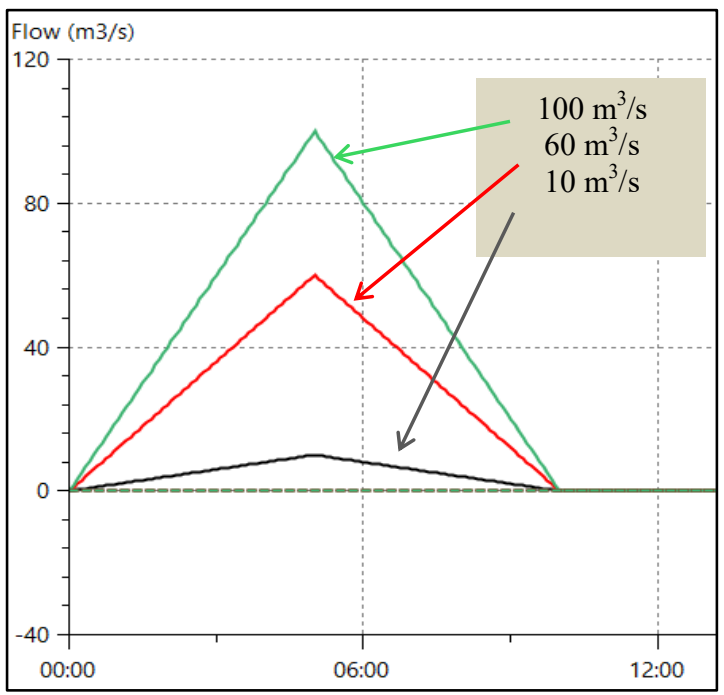

Fig. 3. Inflow representing different rainfall intensity.

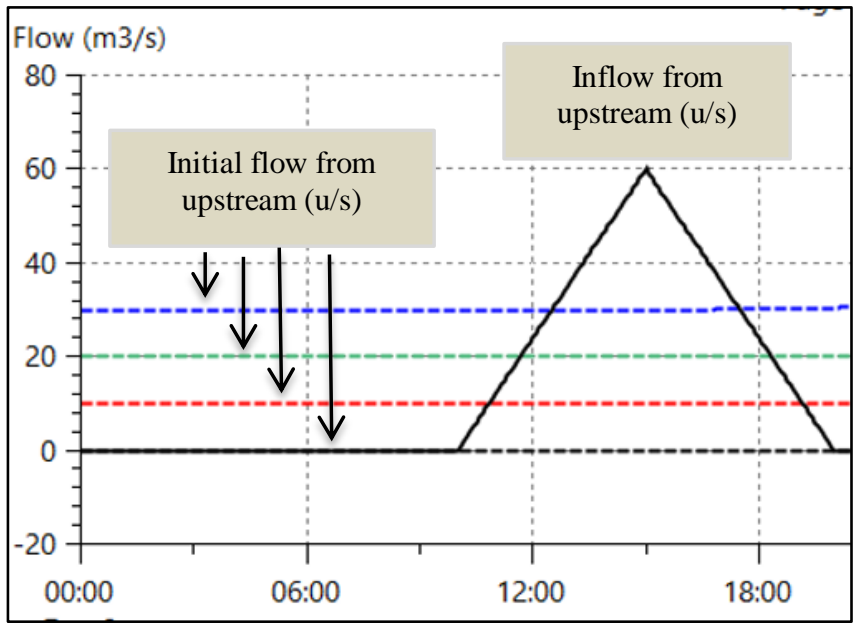

Fig. 4. Inflow hydrograph and different initial flow. 
The close-up view of Sg Relai DTM is shown in Fig. 5 and the cross section at a selected location is shown in Fig. 6. The hydrologic model for Sg Relai (red line) is shown in Fig. 7. The longitudinal section of the channel is shown in Fig. 8 followed by other three figures in Fig. 9 representing longitudinal section for the upstream, midstream and downstream reaches, respectively.

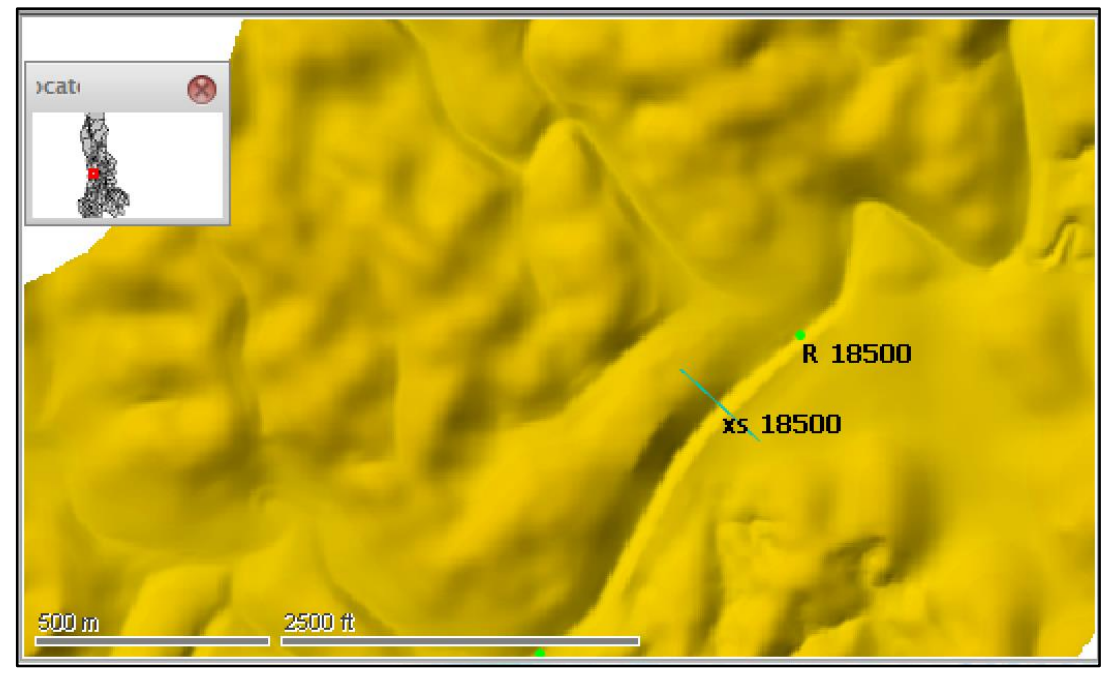

Fig. 5. Sg Relai (DTM) from IFSAR.

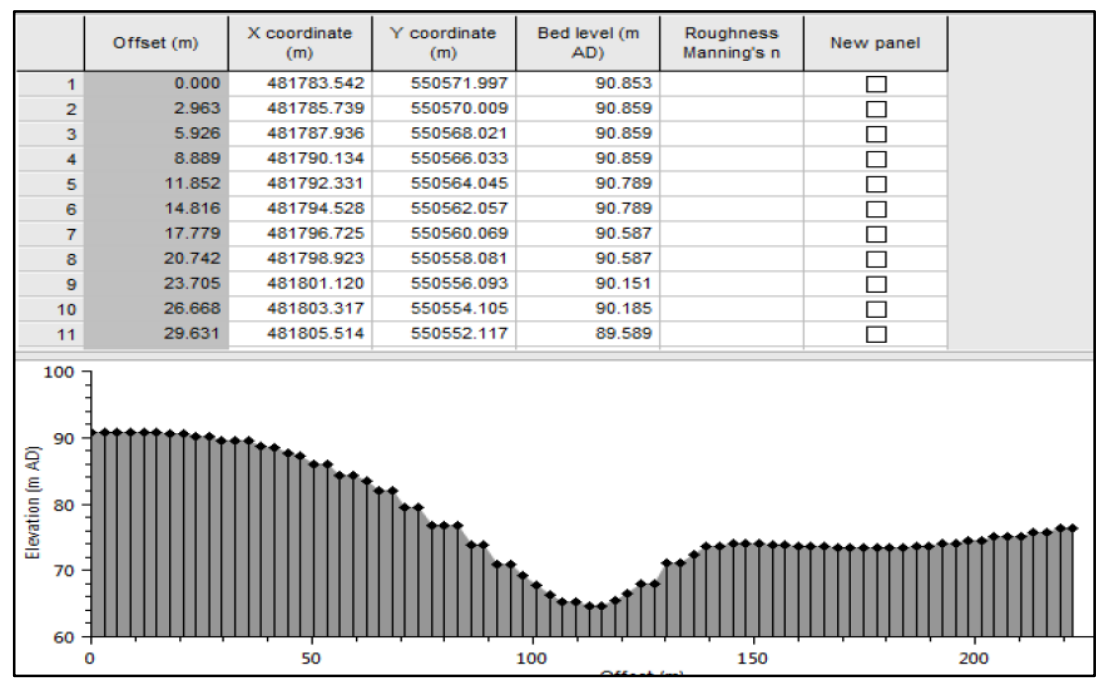

Fig. 6. Channel cross section extracted from DTM. 


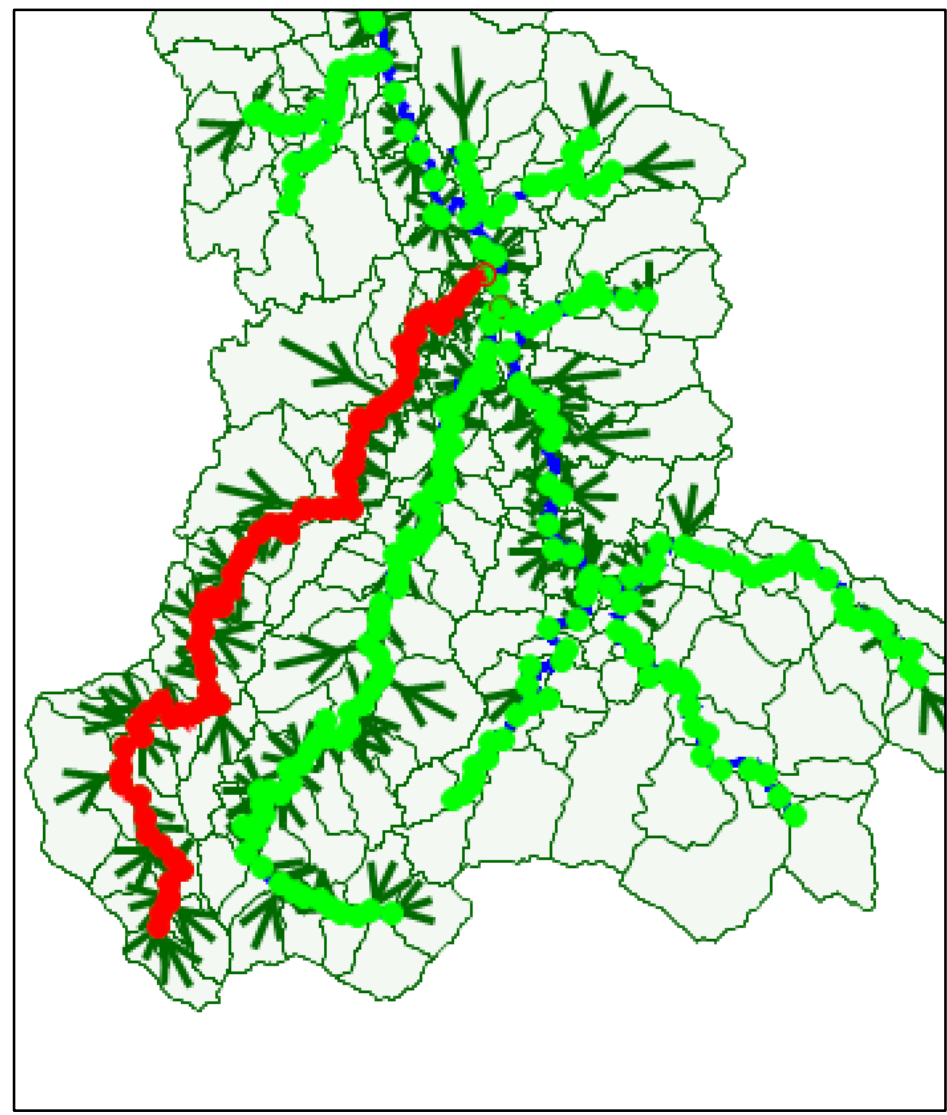

Fig. 7. Hydrodynamic model of Sg Relai (red line).

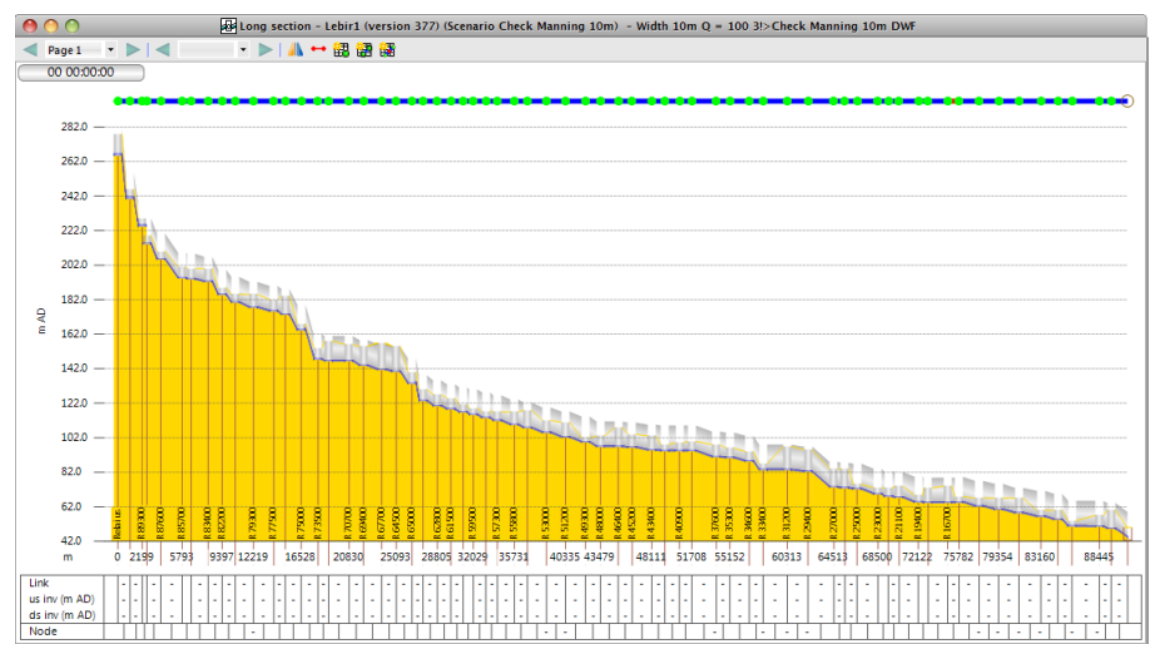

Fig. 8. Modelled longitudinal section for the whole Sg Relai. 


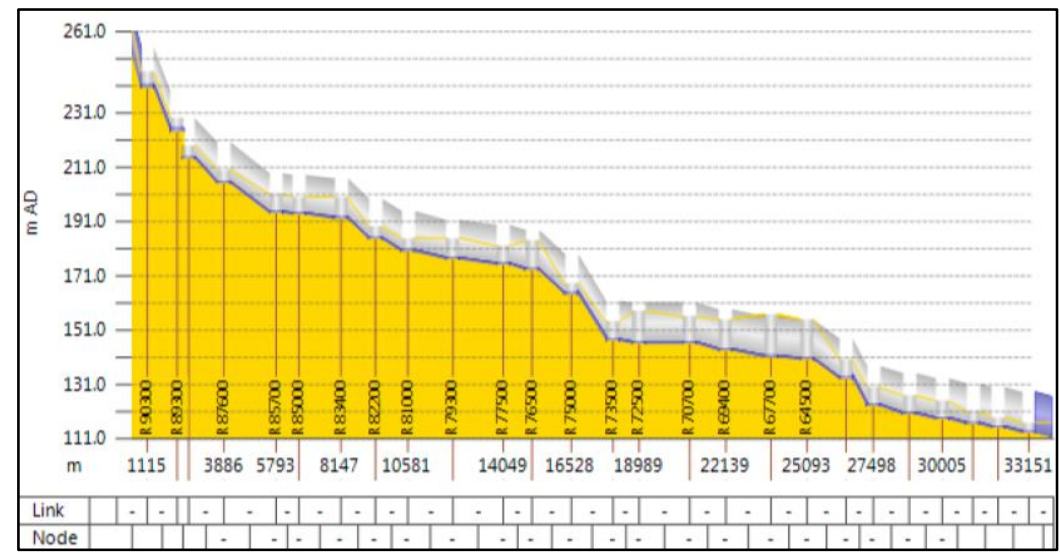

(a)

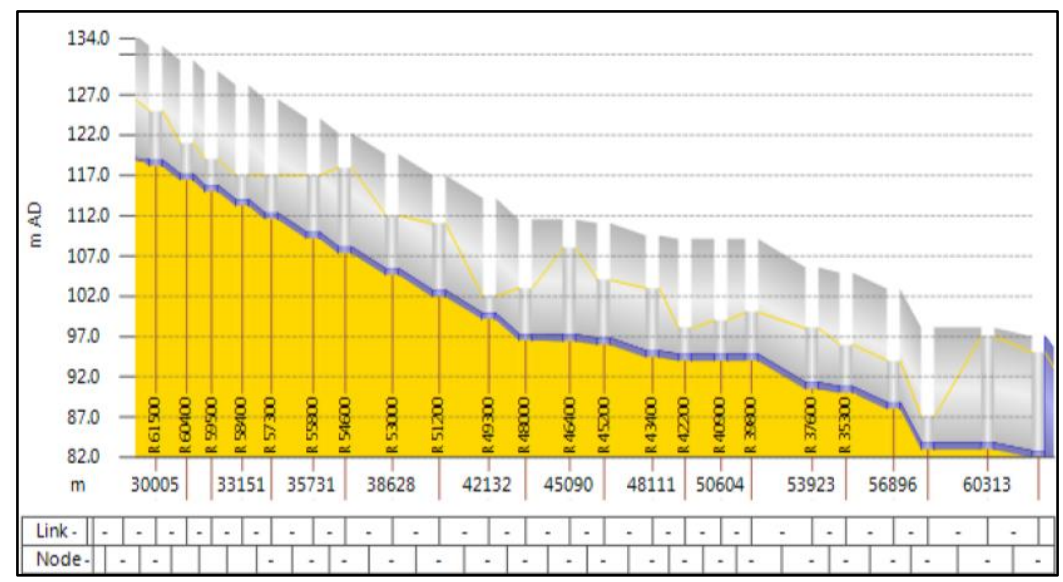

(b)

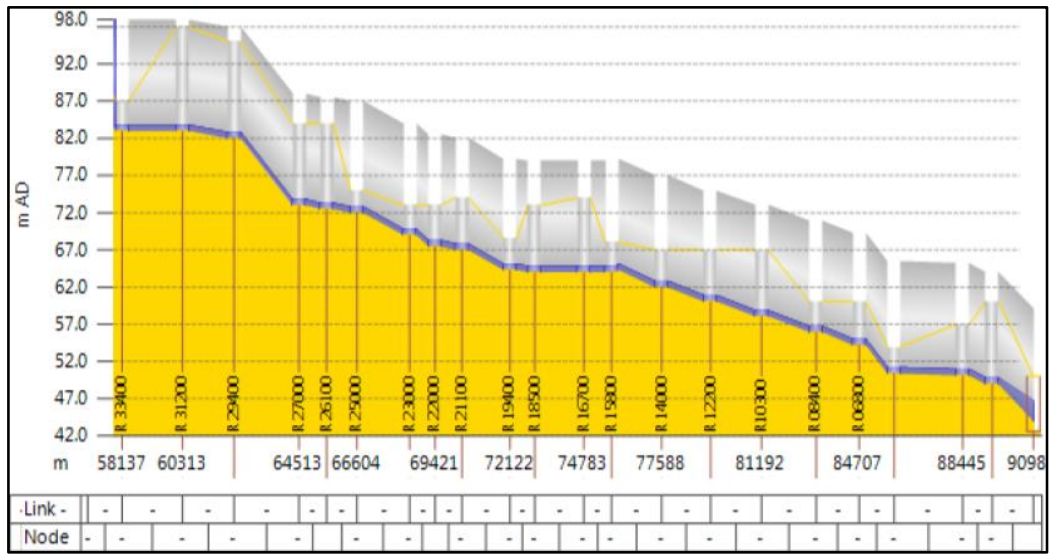

(c)

Fig. 9. (a) Upstream reach; (b) midstream reach; and (c) downstream reach. 
Table 1 shows the summary of the channel gradient with respect to the channel length.

Table 1. Summary of channel gradient for Sg Relai.

\begin{tabular}{|c|c|c|}
\hline Channel Gradient & Total length (m) & \% \\
\hline$<1: 100$ & 5114 & 6 \\
\hline $1: 100-1: 500$ & 14617 & 16 \\
\hline $1: 500-1: 1000$ & 41580 & 46 \\
\hline $1: 1000-1: 3000$ & 16391 & 18 \\
\hline$<1: 3000$ to Flat & 13287 & 15 \\
\hline
\end{tabular}

\section{Results and discussion}

Two factors which were investigated are different rainfall intensity and catchment wetness. Simulation results for various scenarios are presented in Fig. 10 to 13. Table 2 and Table 3 summarised the travelling time for various peak flow and initial flow condition.

\section{Case 1: Different rainfall intensity}

Different rainfall intensity is represented by different peak discharge from the upstream channel which ranging from $10 \mathrm{~m}^{3} / \mathrm{s}$ to $100 \mathrm{~m}^{3} / \mathrm{s}$. To make the model simple to analyse, no additional inflow is added along the channel. From Fig 9, it can be seen that the peak for low discharge occur later than the high discharge. The travelling time which represent the $T_{d}$ will reduce with the increase flow i.e. the increased of rainfall intensity.

Fig 11 and 12 shown the velocity increased as the discharge increased. The sample velocity output indicates that different velocity along the river reach can be captured by the hydrodynamic model. The variation of channel properties which include width, slope and roughness are represented in the model. The velocity ranging from $0.5 \mathrm{~m} / \mathrm{s}$ to $2.5 \mathrm{~m} / \mathrm{s}$ for discharge of $10 \mathrm{~m}^{3} / \mathrm{s}$ to $100 \mathrm{~m}^{3} / \mathrm{s}$ respectively. The increased of velocity will shorten the travelling time of the flood wave.

Table 2. Travelling time for different discharge

\begin{tabular}{|c|c|}
\hline $\begin{array}{c}\text { Peak Discharge } \\
\left(\mathbf{m}^{\mathbf{3}} / \mathbf{s}\right)\end{array}$ & $\begin{array}{c}\text { Travelling time } \\
\text { (hours) }\end{array}$ \\
\hline 10 & 19.0 \\
\hline 60 & 13.5 \\
\hline 100 & 11.5 \\
\hline
\end{tabular}

Case II: Catchment wetness

The catchment wetness is represented by different initial flow added into the model ranging from dry to $30 \mathrm{~m}^{3} / \mathrm{s}$. This initial flow is allow to be steady before flood hydrograph is added at the upstream of the model. From Fig 13, the time of the peak discharge at the downstream occur differently. The time to peak tend to shorten as the initial flow increased. Therefore, if the catchment is wet prior to the occurrence of big storm, the time of 
concentration will be shorten. Furthermore if flow is allowed to enter the channel at the tributaries, then the present of water in the channel shall change the travelling time. This behaviour shall be captured using the hydrodynamic model that is combine with the hydrological model.

Table 3. Travelling time for different initial discharge.

\begin{tabular}{|c|c|}
\hline $\begin{array}{c}\text { Initial discharge } \\
\left(\mathbf{~ m}^{\mathbf{3}} \mathbf{s}\right)\end{array}$ & $\begin{array}{c}\text { Travelling time } \\
\text { (hours) }\end{array}$ \\
\hline Dry & 13.1 \\
\hline 10 & 12.0 \\
\hline 20 & 11.1 \\
\hline 30 & 10.5 \\
\hline
\end{tabular}

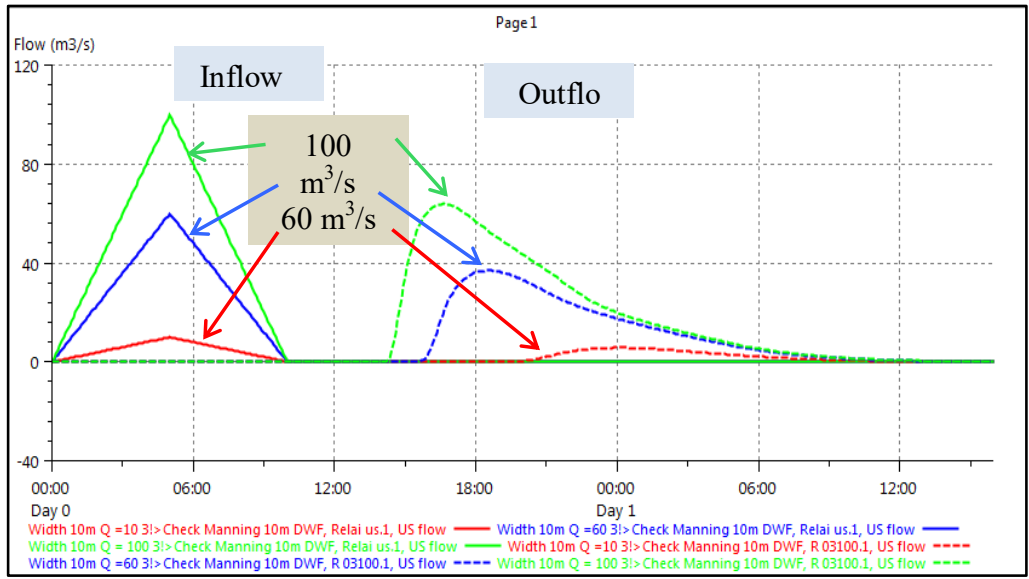

Fig. 10. Hydrograph for various discharge at the upstream and downstream of the river.

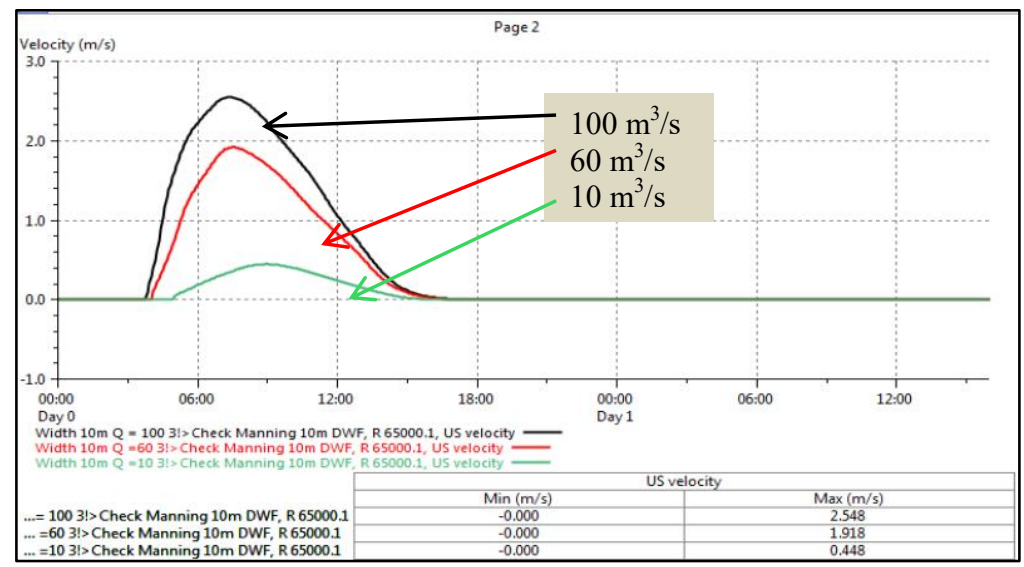

Fig. 11. Velocity at the midstream reach. 


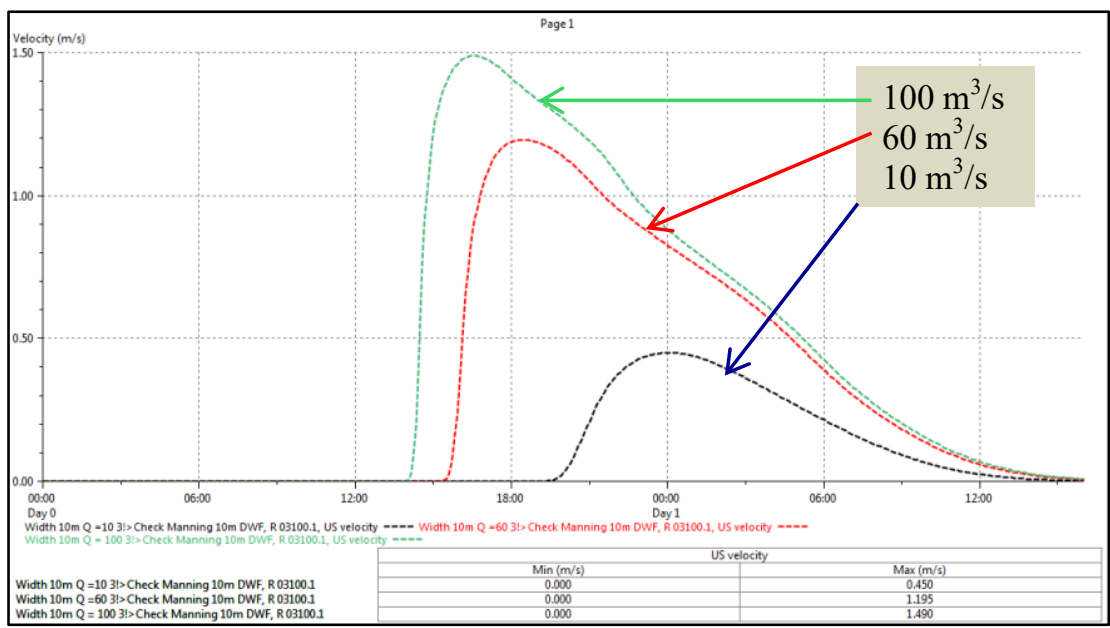

Fig. 12. Velocity at the downstream reach for various discharge.

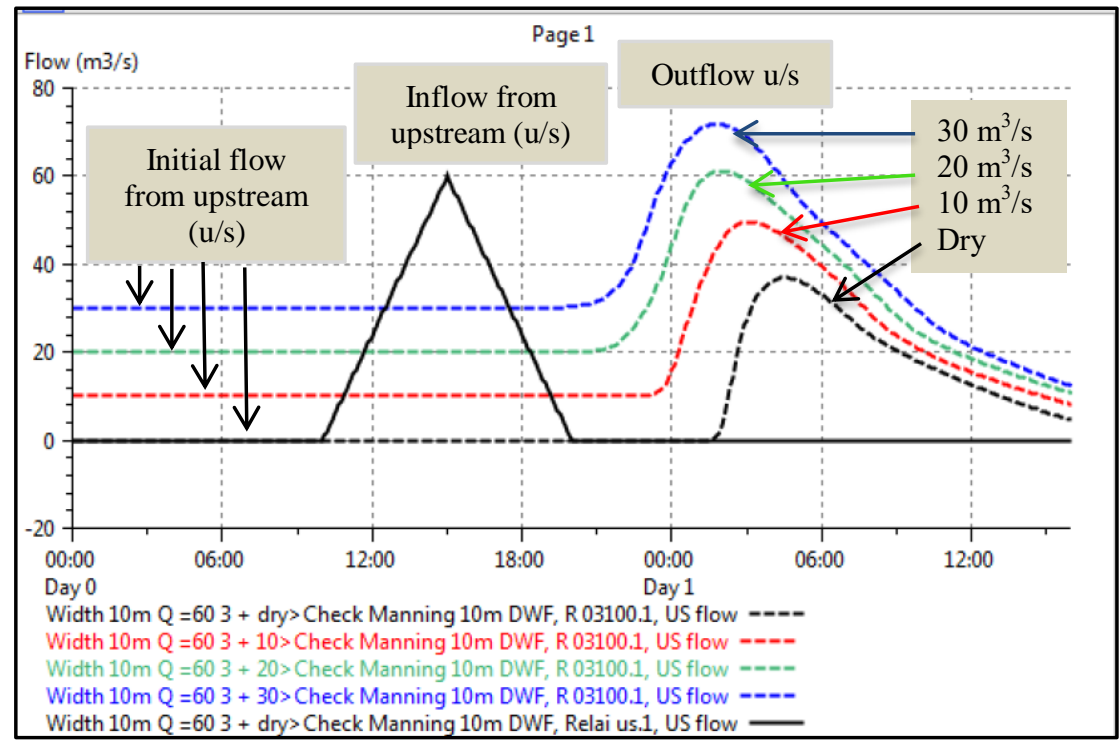

Fig. 13. Flood hydrograph for various initial condition.

\section{Limitation}

The model was developed for inbank only (1-Dimensional) where the effect of storage is not considered. Since the analysis was carried out for moderate flow, the effect of flood plain on the $T_{c}$, during high flow / rainfall intensity can only be examined once the model is extended using 2-Dimensional (2D). 


\section{Conclusion}

Based on the work carried out, some of the conclusions can be stated below:

i. Hydrodynamic model can be developed from IFSAR and satellite image data

ii. The variation of travelling time due to different rainfall intensity can be captured using the hydrodynamic model.

iii. The effect of catchment wetness at the beginning of the flood event can be captured to improve the traveling time of the flood water.

The results achieved from the study proved that the hydrodynamic model capable to improve the estimation of $\mathrm{T}_{\mathrm{c}}$ in the rainfall runoff model for complex condition.

\section{References}

1. USDA-NRCS, National Engineering Handbook Chapter 15: Time of Concentration, $1-15$ (2010)

2. V. T. Chow, D. R. Maidment, and L. W. Mays, Applied Hydrology (1988)

3. I. Kaufmann de Almeida, A. Kaufmann Almeida, S. Garcia Gabas, and T. Alves Sobrinho, Performance of methods for estimating the time of concentration in a watershed of a tropical region. Hydrol. Sci. Journal, 62, 2406-2414 (2017)

4. Innovyze, Infoworks ICM (2017) 